\section{Future of Japanese universities}

SIR - I should like to comment on the article entitled "What future for Japanese universities?" (Nature 372, 711; 1994). Great expectation is being placed on Japanese universities to undertake serious self-reform. Since the end of the Second World War, Japan has experienced rapid and substantial changes, both socially and economically. These changes should, as a matter of course, have induced reform in both the content and approach of the universities' education and research programmes.

The greatest challenge facing Japanese universities is the enhancement of quality. A number of issues require urgent solution, including a lack of diversity in course curricula, a lax evaluation system and the resulting lack of competition, a closed and rigid system of institutional administration and a weak financial base.

Following guidelines issued by the University Council, individual universities have launched serious reforms aimed at creating institutional identity, improving educational quality, raising the level of education and research by expanding and reforming graduate programmes, and increasing the flexibility of higher education systems to accommodate the needs for adult and lifelong education.

But your article contains some misunderstandings about national universities in Japan. The first concerns the allocation of research funds. These are allocated in two ways, one based on the size of the recipient university, and the other on specific research proposals. Allocations based on a university's size provide the basic funding necessary to maintain its education and research operations, and are not allocated according to an evaluation of individual projects. It is up to the university to decide how these funds are distributed.

Chief among the allocations based on research proposals are the grants-in-aid for scientific research provided by the Ministry of Education, Science and Culture (Monbusho). These grants are awarded according to the independent judgement of the Committee on Scientific Research Grants within Monbusho's Science Council. The committee's review is assisted by some 2,000 university researchers, many of whom are nominated by the Science Council of Japan (a body representing Japanese scientists). The selection of research projects for funding is therefore made through strictly impartial and objective peer review. Apart from individual research grants, a similar allocation method for allocating funds is applied to support for large-scale science projects, based on thorough deliberation by the Science Council and its specialized subcommittees, and not arbitrarily by officials of Monbusho.

Second, on the administrative autonomy of Japan's national universities, these are free to plan and implement, within the limits of their budgets, their own education and research programmes. Decisions are made at faculty meetings and by a university senate comprising representatives from all the faculties. The problem is that these faculty meetings and university senates do not necessarily function effectively. And, as pointed out in your article, there is no system for objectively evaluating university education and research activities carried out under conditions of administrative autonomy. Thus the system for allocating resources based on such an evaluation is not working particularly well.

We are fully aware of the need to solve these problems. But this cannot be automatically accomplished by "reconstituting the national universities as public corporations". The danger in viewing the administrative problems of Japanese universities in terms of their status as institutions is that we may fail to grasp the true nature of these problems. What is important now is to introduce the principle of competition and to establish an objective evaluation system in Japanese universities.

\section{Katsuhide Kusahara}

(Deputy Director-General,

Higher Education Bureau)

Ministry of Education,

Science and Culture,

3-2-2 Kasumigaseki,

Chiyoda-ku,

Tokyo, 100 Japan

\section{Karl Popper}

SIR - Sir Karl Popper was worthy of all the praise in the obituary (Nature 371, 478; 1994) by Hermann Bondi who, however, may have overestimated the living by stating that "the scientific community has lost the philosopher who many of us feel illuminated, far more than any other, the way in which we [ought to?] work"

In the preface to The Logic of Scientific Discovery, Popper states: "If we ignore what other people are thinking, or have thought in the past, then rational discussion must come to an end, though each of us may go on happily talking to himself." Bondi may be correct in supposing or knowing that investigators cannot ignore contemporary thought when trying to solve problems in branches of science, technology or medicine held in esteem today. Genetics, immunology and molecular biology have offered spectacular solutions to medical problems of our brave old species. It may be permissible to forget thoughts in the past on problems solved or solvable by modern science but less so to overlook the fact that numerous multifactorial and other complex problems remain unsolved and might find solutions in our forefathers' thoughts.

Many problems drifted into fashion in the 1960 s and 1970 s and, though unsolved, they still belong in them, thus obscuring from our view promising approaches based on careful observations by physicists, chemists and physiologists decades or even centuries ago. Admirers of Popper have considered most disturbing conclusions about their problems based on the revival, by scientists "around the corner", of old approaches. Do many readily spot Popper's "black swan", the one that falsifies our conviction that (all) swans are white? Should authors be encouraged to define and put down potential falsifiers of their messages?

The above quotation was preceded by “. . , whenever we propose a solution to a problem, we ought to try as hard as we can to overthrow our solution, rather than defend it. Few of us, unfortunately, practise this precept; but other people, fortunately, will supply the criticism. . .". Are many of us able to provide a criticism based on thought in the past? Popper might have welcomed my [bracketed] addition to Bondi's first sentence.

\section{Johan Ahiqvist}

Sibbvik,

SF-25830 Västanfjärd,

Finland

\section{Daedalus misses the boat}

SIR - Daedalus ${ }^{1}$ describes motion sickness as arising from the gut, despite well known overwhelming evidence to the contrary. Numerous studies (for example, ref. 2) involving humans and animal models have shown that the vestibular labyrinth is essential for motion sickness. In contrast, denervation of the gut does not prevent motion sickness.

Daedalus also states that motion sickness "occurs only in vehicles". In fact, motion sickness can be induced by making side-to-side head movements while spinning oneself in circles or by visual special effects when one is sitting stationary.

Finally, one has to wonder how well Daedalus expects to breathe after the DREADCO engineering servo-unit cancels all movement of the diaphragm.

\section{Alan D. Miller}

Rockefeller University,

1230 York Avenue,

New York,

New York 10021-6399, USA

1. Jones, D. Nature 373, 662 (1995)

2. Money, K. E. Physiol. Rev. 50, 1-39 (1970). 